\title{
Design of Patch Antenna with Inverted U Slot for WiMax Application
}

\author{
B. Neeththi Aadithiya, N.V. Andrews and M. Manikandan
}

Department of Electronics and Communication Engineering, M. Kumarasamy College of Engineering (Autonomous), Karur-639113,Tamil Nadu, India; neethiece@gmail.com, andrewsnv.ece@mkce.ac.in, manikandanm.ece@mkce.ac.in

\begin{abstract}
Objectives: To design an antenna for WiMax application radiating at a frequency of $2.5 \mathrm{GHz}$. Methods/Statistical Analysis: In the recent years with the rising development in digital systems, the demand for antennas which is of low profile, light weight has improved. This paper details about the design of patch antenna which is square in shape. Findings: The preferred operating frequency for the radiating patch is $2.5 \mathrm{GHz}$. The suggested patch can be utilized in the WIMAX. In order to achieve the effective radiation the slot is created on the square patch. The above defined radiating element is simulated with the use of ADS software. The Simulated design offers return loss of -13 DB at the designed frequency. Applications/Improvements: The radiating element is intended to use for WiMax.
\end{abstract}

Keywords: Patch, Slot, Square Shape, WiMax, ADS

\section{Introduction}

A Distinctive electrical device or a metallic structure which is capable of transmitting electromagnetic waves is termed as antennas ${ }^{1}$. The antennas forge ahead with superior performance requirement as there is a rapid increase in wireless technologies. The technical advancements allow the deployment of antennas in applications such as under water communication, navigation systems, body centric wireless communication and so on². The design of a patch is preferred as it offers low profile, less weight and low cost. In spite of the advantages it lacks with the narrow bandwidth $\frac{3-5}{-}$. WiMax hypothetically can have scope of up to $50 \mathrm{~km}$ span. The operating frequency range for WiMAX antennas is between 2.2 -3.4 GHZ. The suggested design is indented to operate for WiMAX application.

\section{Research Methodology}

\subsection{Patch Antenna with Two Slots Forming E Shape}

The performance improvement is achieved with the use of slots and rectangular patch. The slots are located collat- eral to each other and the design obtained is patch which is $\mathrm{E}$ in shape. The rectangular patch is located above the ground plane separated by the foam which is of thickness $\mathrm{h}$. The rectangular patch is fed with the help of coaxial probe $50 \mathrm{ohms} \frac{6-8}{\text {. }}$. The antenna design is presented in Figure 1.

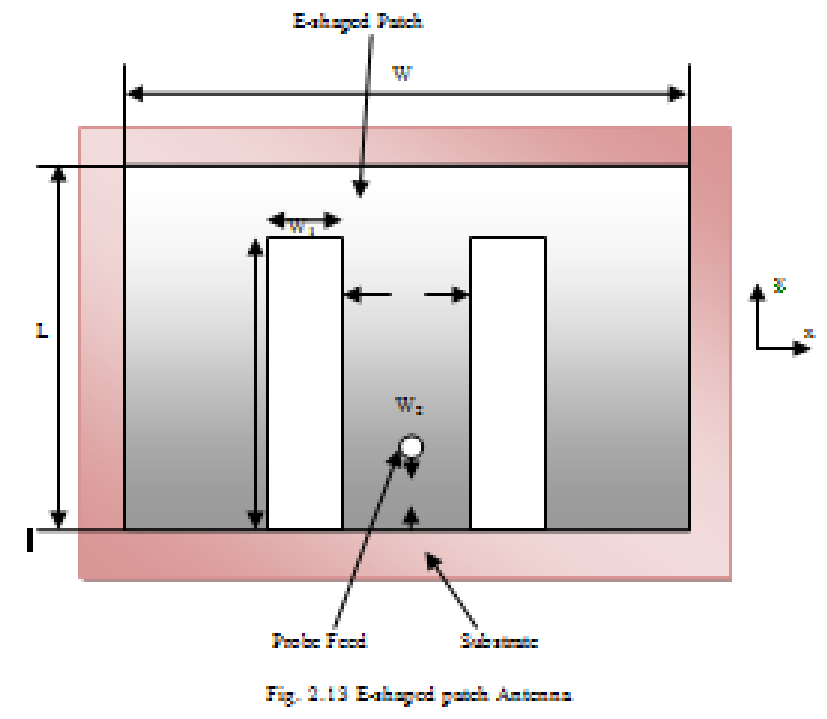

Figure 1. Patch antenna with two slots. 
The Two parallel plates highly contribute for the broadband operating nature of the suggested patch design. The radiating element aims to operate in two different frequencies namely $2.12 \mathrm{GHZ}$ and $2.66 \mathrm{GHZ}$. The simulations are performed with the use of IE3D tool.

\subsection{Microstrip Patch Y-shaped Antenna}

The suggested radiating element is modeled above the Flame resistant material is available in Figure 2. The substrate is selected with Relative permittivity of $4.4 \mathrm{~mm}$ and thickness is $1.6 \mathrm{~mm}$. The ground plane extends upward about $6 \mathrm{~mm}$. The antenna is fed with the coaxial line with the $50 \mathrm{ohms}$ impedance ${ }^{7-12}$. The return loss obtained is about $-10 \mathrm{DB}$ at the operating frequencies and shows the VSWR values less than 2.The antenna shows the Omnidirectional radiation pattern.

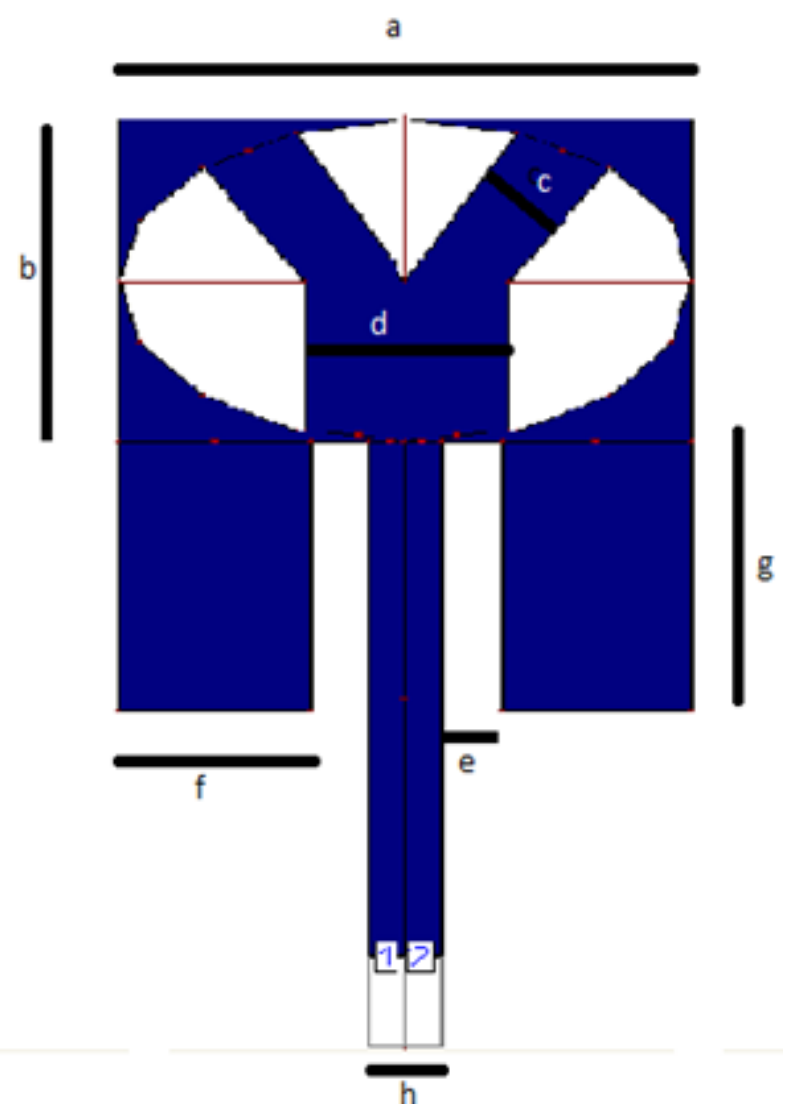

Figure 2. Antenna design.

\subsection{Antenna with Four Slots}

The suggested W shaped patch is in Figure 3. Lower plane is made different by foam and second dielectric substrate is FR4.The foam is of $3.4 \mathrm{~mm}$ height and $\varepsilon \mathrm{r}$ is about 1.07 .
The second dielectric substrate material FR4 extends upward with $1.6 \mathrm{~mm}$. The chosen $\varepsilon \mathrm{r}$ is 4.4 . The Y Shaped radiating element aims to operate in $4.5 \mathrm{GHZ}$ Frequency band. The performance results of the design is $65.3 \%$.The simulated antenna shows the better return loss values less than $-10 \mathrm{DB} \frac{13-15}{}$.

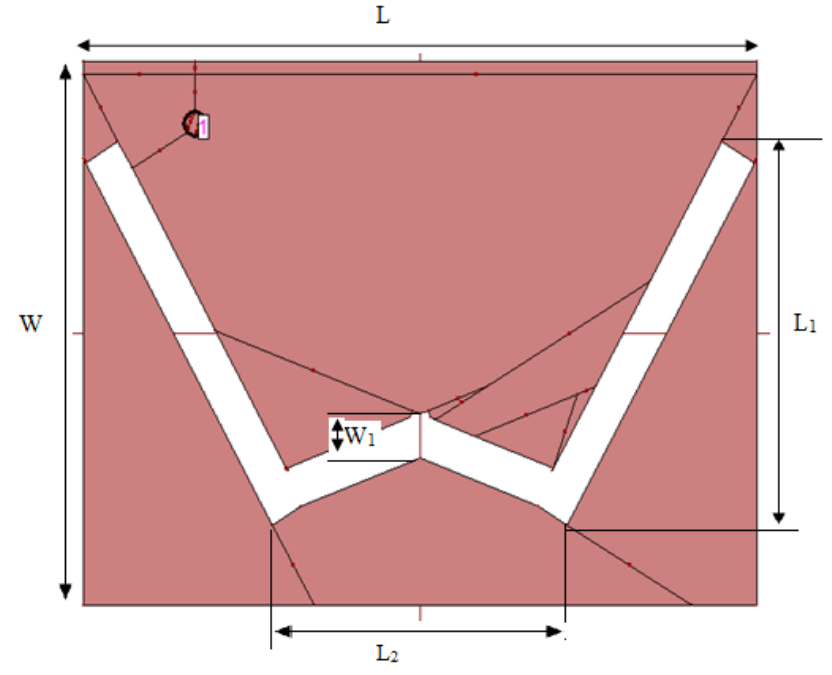

Figure 3. Patch antenna.

\section{Antenna Design}

The design is equal sided in dimensions. The structure of the radiating element is elaborated in Figure 4. The equal sided patch design is arranged on the top of Flame resistant substrate.

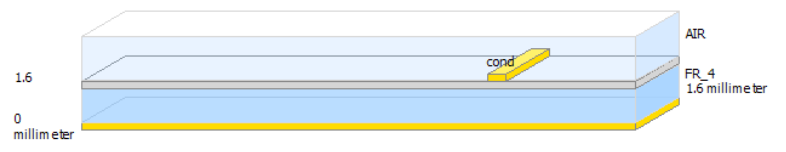

Figure 4. Proposed antenna structure.

The 3D prospect of antenna is available in Figure 5. Few things have to be shown attention when designing the radiating patch are as follows performing frequency, material on the top of which the radiating element is to be raised, materials permittivity. The scale values for the prompted equal sided structure are obtained using the relations. The side dimensions are $29.2 \mathrm{~mm}$. 


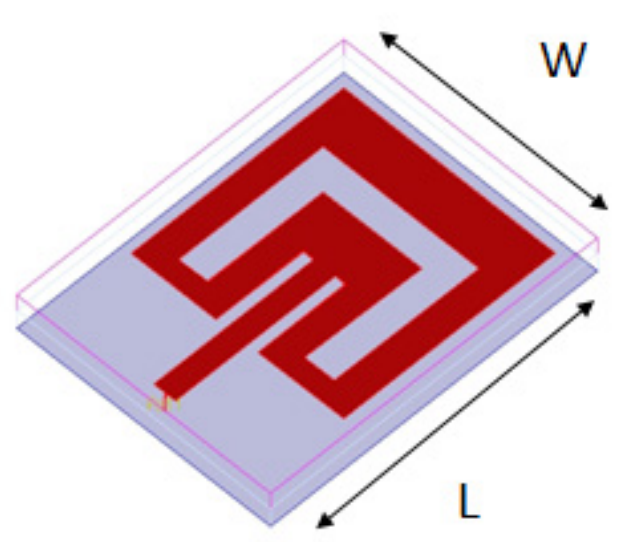

2.

Figure 5. Proposed antenna design in $3 \mathrm{D}$ view.

The preferred substrate material is FR4 (Lossy) and the permittivity value is 4.4 and the thicknes chosen for the design is $1.6 \mathrm{~mm}$. Larger conducting area of the design is built with copper and the consistency of the layer is 35 micron.

Figure 6 shows the maximum current distribution on the structure. The infinite ground concept is applied for the proposed structure. It is intended in such a way that it intrudes within the substrate. Square shaped patch is designed with a slot on it to have the better operating results. The feed offered for the antenna is edge feeding with 50ohms impedance.

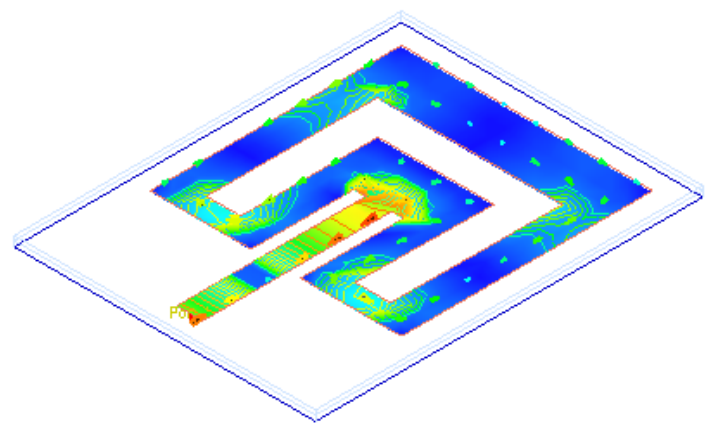

Figure 6. Current and maximum radiation.

\section{Results and Discussions}

The designed patch with inverted U Shape is simulated using the advanced design system software. The methods of moments are used in ADS software. The S11 parameter simulation is nearly at $-13 \mathrm{~dB}$ on the designed frequency
2.5 GHZ is evidenced from Figure 7 and 8 . The $\$ 11$ parameter determines the effectiveness of the antenna design.

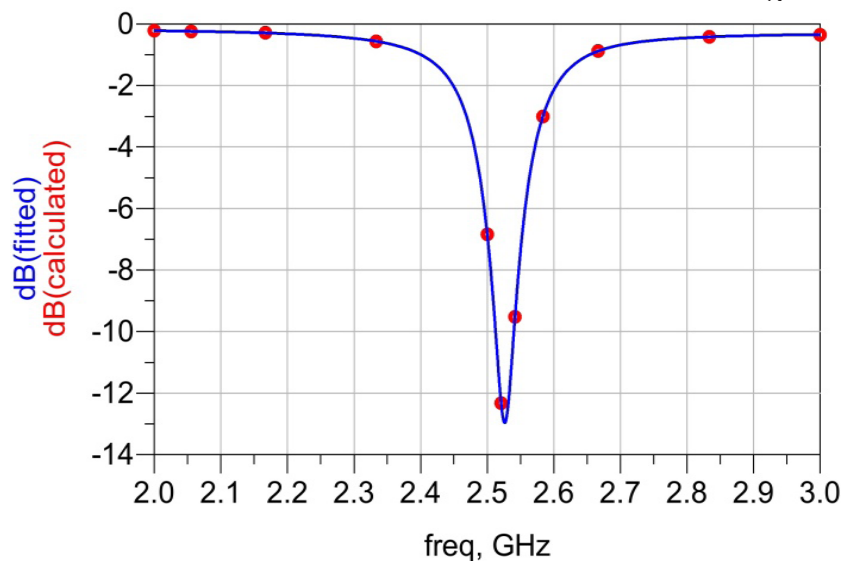

Figure 7. Magnitude plot of S11.

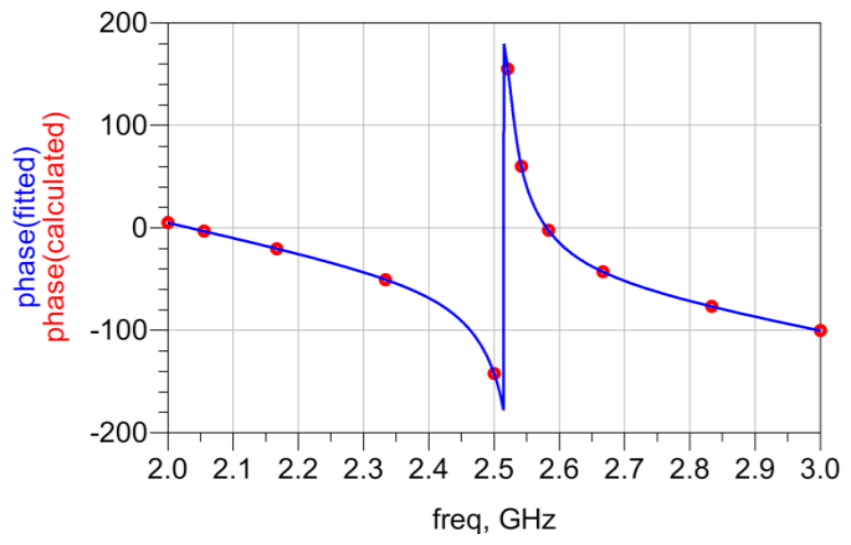

Figure 8. Phase plot.

The values obtained from S11 parameter offers the results about the supplied power and the power that rebounds. The return loss is $-13 \mathrm{DB}$. The results show that the maximum power is diffused. The pattern is simulated in Figure 9 to analyze the strength of power in terms of direction. Figure 10 shows the capability of the wave to oscillate in different directions.
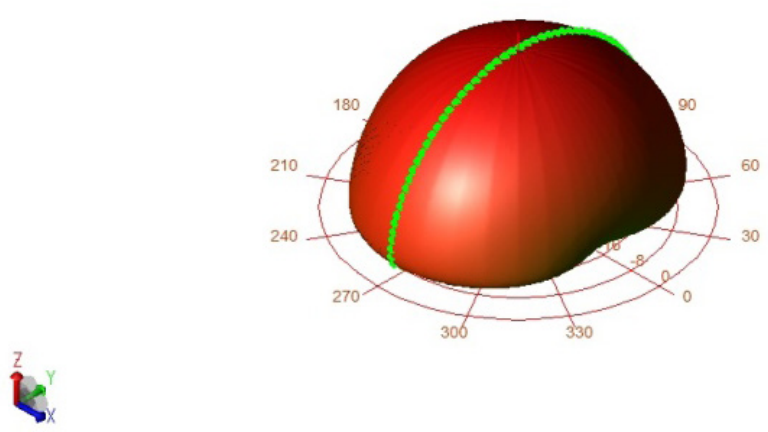

Figure 9. 3D view of radiation pattern. 


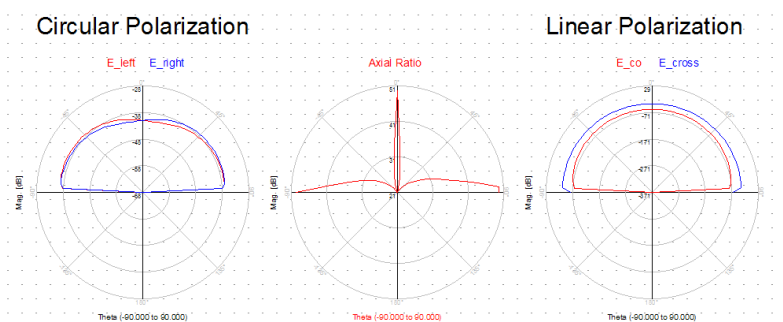

Figure 10. 2D view of circular and linear polarization.

The value of Gain is $6.88498 \mathrm{DB}$ available in Figure 11 and the Directivity is 6.89547 .

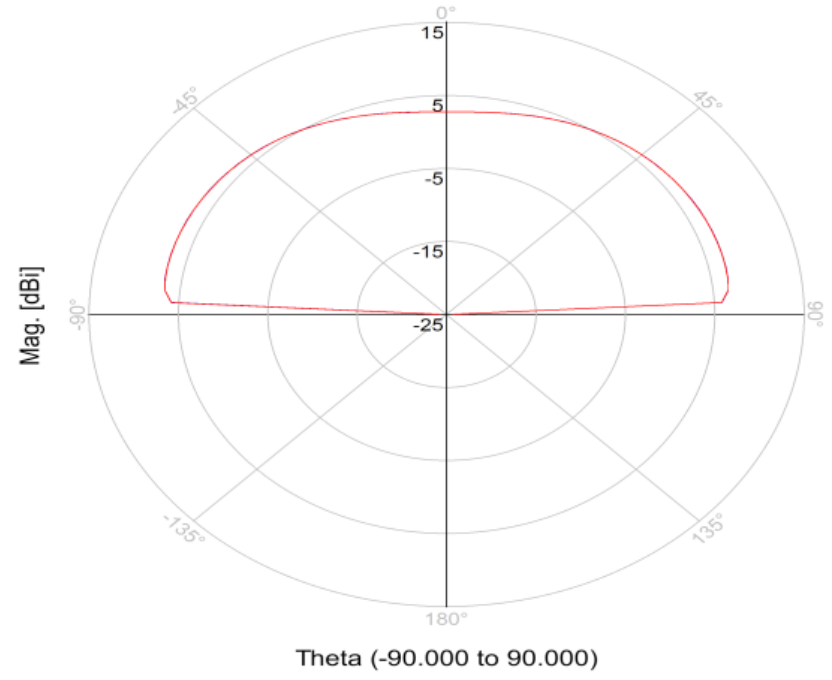

Figure 11. Plot of patch antennas gain.

\section{Conclusion}

The simulated square shaped patch antenna shows the optimal results for WiMAX operating environment with $-13 \mathrm{DB}$ return loss and Omni-directional radiation pattern. $83.2 \%$ is the effectiveness. The introduction of one or more slots in different shapes with the same patch dimensions and the use Two dielectric substrate materials such as foam can increase the bandwidth is the future scope of this work.

\section{References}

1. Rajan SP, Paranthaman M, Vivek C. Design and enhancement of wideband re-configurability using two e-shaped patch antenna, Asian Journal of Research in Social Sciences and Humanities. 2016; 6(9):317-27. Crossref.

2. Duan Z, Yong-Xin G, Rui-Feng X, Je M, Dim-Lee K. Differentially fed dual-band implantable antenna for biomedical applications, IEEE Transactions on Antennas and Propagation. 2012; 60(12):5587-95. Crossref.
3. Paranthaman M, Vijayprasath S, Palanivel RS. Design of a frequency tunable patch antenna using HFSS, International Journal of Advanced Research Trends in Engineering and Technology. 2016; 3(7):69-72.

4. Liu C, Yong-Xin G, Xiao S. Compact dual-band antenna for implantable devices, IEEE Antennas and Wireless Propagation Letters. 2012; 11:1508-11. Crossref.

5. Duan Z, Yong-Xin G, Rui-Feng X, Je M, Dim-Lee K. Design and in vitro test of a differentially fed dual-band implantable antenna operating at MICS and ISM bands, IEEE Transactions on Antennas and Propagation. 2014; 62(5):2430-39. Crossref.

6. Li-Jie X, Yong-Xin G, Wu W. Miniaturized dual-band antenna for implantable wireless communications, IEEE Antennas and Wireless Propagation Letters. 2014; 13:1160-63. Crossref.

7. Karacolak T, Hood AZ, Topsakal E. Design of a dual-band implantable antenna and development of skin mimicking gels for continuous glucose monitoring, IEEE Transactions on Microwave Theory Technology. 2008; 56(4):1001-08. Crossref.

8. Karacolak T, Cooper R, Topsakal E. Electrical properties of rat skin and design of implantable antennas for medical wireless telemetry, IEEE Transactions on Antennas and Propagation. 2009; 57(9):2806-12. Crossref.

9. Liu C, Guo YX, Xiao S. Compact dual-band antenna for implantable devices, IEEE Antennas Wireless Propagation, Letters. 2012; 11:1508-11. Crossref.

10. Rajan SP, Vivek C, Paranthaman M. Feasibility analysis of portable electroencephalography based abnormal fatigue detection and tele-surveillance system, International Journal of Computer Science and Information Security. 2016; 14(8):711.

11. Paranthaman M, Berlin A. Design of adaptive changing structures with bandwidth control for wideband applications, International Journal of Innovative Research in Electrical, Electronics, Instrumentation and Control Engineering. 2017; 5(2):26-28.

12. Rajan SP, Dinesh T. Analysis of human brain disorders for effectual hippocampus surveillance, International Journal of Modern Sciences and Engineering Technology. 2015; 2(2):38-45.

13. Wel H, Jin R, Geng J. E-shape patch with wideband and circular polarization for millimeter wave communication, IEEE Transactions on Antennas and Propagation. 2008; 56(3):893-95. Crossref.

14. Paranthaman M, Shanmugavadivel G. Design of frequency reconfigurable e-shaped patch antenna for cognitive radio, International Journal of Applied Engineering Research. 2015; 10(20):16546-48.

15. Paranthaman M. T-shape polarization reconfigurable patch antenna for cognitive radio. Third International Conference on Science Technology Engineering and Management (ICONSTEM), Chennai; 2017. p. 927-29. Crossref. 